\title{
Além do mecanicismo e do vitalismo: a "normatividade da vida" em Georges Canguilhem
}

\author{
RODOLFO FRANCO PUTTINI" \\ ALFREDO PEREIRA JÚNIOR •
}

Discutimos a epistemologia das ciências da vida e das ciências da saúde de Georges Canguilhem, revendo sua crítica à concepção mecanicista da normalidade e da patologia e seu posicionamento frente ao vitalismo. Sugerimos que, enfatizando o conceito de "normatividade da vida", Canguilhem teria apontado para uma superação da oposição entre mecanicismo e vitalismo. Para tal, fazemos uma breve comparação da "normatividade da vida" com o conceito contemporâneo de auto-organização de Michel Debrun, argumentando que a emergência da norma vital se situa num estágio secundário de um processo de (auto-)organização da vida e, portanto, tal normatividade não teria a conotação vitalista, erroneamente atribuída a Canguilhem.

Palavras-chave: normatividade da vida, normal e patológico, mecanicismo, vitalismo, auto-organização.

Recebido em: 04/09/2006.

Aprovado em: 17/04/2007. 


\section{Introdução}

O sucesso da física de Galileu e Newton trouxe, para as demais ciências, um apelo para que se adequassem a seu modelo explicativo (HULL, 1971). Esse modelo era constituído pelo método hipotético-dedutivo, guiando o planejamento e execução de observações e experimentos de comprovação. As hipóteses formuladas eram sempre do tipo causal, em que determinado fator por exemplo, uma força atuando sobre um corpo - gera determinado efeito por exemplo, a alteração da velocidade desse corpo. Com esse tipo de modelo Newton conseguiu, utilizando apenas três esquemas causais (as famosas três leis de Newton), explicar o movimento dos corpos.

Tal concepção de causalidade reduzia a três as possibilidades explicativas levantadas por Aristóteles:

a) causas materiais, como a massa do corpo em movimento;

b) causas formais, como a forma retilínea ou circular do movimento; e

c) causas eficientes, como a força gravitacional atuando sobre o estado de movimento do corpo.

Desse modelo explicativo foram excluídas as causas finais propostas por Aristóteles, que eram freqüentemente evocadas para explicar os fenômenos da vida e da saúde. Mesmo no plano do conhecimento comum, costumamos fazer raciocínios finalistas ou teleológicos para explicar os fenômenos da vida, especialmente aqueles relacionados ao comportamento animal. Entendemos que animais realizam diversas ações objetivando - de modo intencional ou não - atingir certas metas, como a sobrevivência individual e a reprodução da espécie.

Como se poderia conciliar essa concepção teleológica com o modelo da física newtoniana? Os chamados vitalistas, proponentes da existência de uma força vital adicional às forças físicas conhecidas, insatisfeitos com aquele modelo mecanicista do universo, não poderiam simplesmente contrapor, à monumental física de Galileu e Newton, os princípios metafísicos de Aristóteles e filósofos medievais. Para comprovar a existência da teleologia, tiveram que se engajar em experimentos científicos do mesmo estilo daqueles empregados por Galileu para demonstrar que a Terra se move.

$\mathrm{Na}$ última década do século XIX, Hans Driesch tentou comprovar a existência de um princípio vital teleológico (intitulado entelechia), por meio de um experimento no qual dividiu ao meio um embrião de ouriço-do-mar que se 
encontrava numa fase de desenvolvimento composta de duas células (blastômeros). Observou-se que um blastômero veio a se desenvolver por inteiro, regenerando a parte perdida. Este resultado foi interpretado por Driesch como indicador da ação da entelechia sobre o blastômero, conduzindo-o para uma meta (telos), que seria a forma do ouriço em sua completude (vide discussão em Weydert, 2004).

A medicina homeopática já se encontrava desenvolvida nessa época, em particular no trabalho de Samuel Hahnemann. A homeopatia se afirmou como prática clínica de promoção da saúde, através do princípio da "cura pelo semelhante", isto é, promovendo a cura de uma doença através da utilização de um princípio ativo semelhante aos fatores causadores da doença. Assumindo um dinamismo vital que opera num domínio não abarcado pelas categorias explicativas do mecanicismo, o movimento homeopático adotou uma estratégia pragmática, procurando comprovar a veracidade de seus princípios através dos efeitos benéficos oriundos de sua aplicação.

No século XIX também encontramos a grande síntese realizada por Bernard (1865), adequando o modelo mecanicista aos avanços do conhecimento e da prática médicas. Nesse momento, a própria física expandia seus horizontes, com o eletromagnetismo de Maxwell, a termodinâmica de Clausius e a teoria cinética dos gases de Boltzmann, introduzindo novos conceitos que vieram a ter importante influência nas ciências da vida e da saúde: os conceitos de campo magnético e de equilíbrio termodinâmico.

Os estudos de Claude Bernard sobre os mecanismos de regulação orgânica possibilitaram, em conjunção com os avanços da física, a formulação do conceito de homeostase por Walter Cannon em 1928 (vide BAYLISS, 1966). Segundo Bernard, a vida depende da "constância do ambiente interno", ou seja, de um equilíbrio que resulta de "uma compensação contínua e delicada, estabelecida pelo mais sensível balanceamento" (BERNARD, 1865). Tal concepção de equilíbrio dinâmico amplia o modelo mecanicista em direção ao organicismo, sem, contudo, entrar em contradição com as premissas básicas do primeiro.

O movimento positivista francês, que possivelmente teve em Augusto Comte seu maior expoente, pode ser entendido como uma iniciativa fundamentalista de preservação dos princípios da ciência moderna, e de sua aplicação para o aperfeiçoamento da sociedade humana. Nesse contexto se forjaram os conceitos de normalidade e patologia posteriormente discutidos por George Canguilhem. 
Neste ensaio, ${ }^{1}$ discutimos em que medida Canguilhem é bemsucedido em sua crítica a uma visão mecanicista do normal e do patológico, e em que medida ele recai numa posição vitalista. Sugerimos a possibilidade de que ele tenha superado a oposição entre mecanicismo e vitalismo, antecipando os atuais modelos de sistemas dinâmicos não-lineares. Para tal, fazemos uma breve comparação com o conceito de auto-organização proposto por Michel Debrun (1996).

\section{A discussão da normalidade e da patologia}

O conceito de normatividade da vida faz parte do núcleo epistemológico central do pensamento de Canguilhem. Inicialmente ele foi apresentado numa discussão crítica do conceito de normalidade, amplamente utilizado na clínica médica.

Em sua tese de doutorado (Ensaio sobre alguns problemas relativos ao normal e ao patológico, 1943), o entendimento de Canguilhem sobre a racionalidade médica era marcado por sua definição de medicina como sendo uma atividade clínica e terapêutica, uma atividade técnica e/ou "uma arte situada na confluência de várias ciências, mais do que uma ciência propriamente dita [...] de instauração e restauração do normal, que não pode ser inteiramente reduzida ao simples conhecimento" (CANGUILHEM, 1995, p. 16, Introdução). Nesse sentido, deixou claro que seu trabalho seria "um esforço para integrar, à especulação filosófica, alguns dos métodos e das conquistas da medicina", ressaltando que "tivemos a ambição de contribuir para a renovação de certos conceitos metodológicos, retificando sua compreensão pela influência de uma informação médica" (CANGUILHEM, 1995, p. 16).

Canguilhem tinha como objetivo final desenvolver uma metodologia apropriada às ciências da vida, relacionando-as à atividade terapêutica na medicina. Tal objetivo contrastava com o panorama epistemológico da época:

a identidade real dos fenômenos vitais normais e patológicos, aparentemente tão diferentes, aos quais a experiência humana atribuiu valores opostos, tornou-se durante o século XIX uma espécie de dogma cientificamente garantido, cuja extensão no campo da filosofia e da psicologia parecia determinada pela autoridade que os biólogos e os médicos lhe reconheciam (CANGUILHEM, 1995, p. 23). 
Ele considerou problemático o uso então realizado dos conceitos de normalidade e patologia na prática médica. Notou a dimensão do problema através da classificação de nosologia somática ou de fisiologia patológica, na época: "o problema do normal e do patológico pode, do ponto de vista médico, dividir-se em problema teratológico e em problema nosológico, e este último, por sua vez, em problema de nosologia somática ou de fisiopatologia, e em problema de nosologia psíquica ou de psicopatologia" (CANGUILHEM, 1995, p.16). Tal classificação expressaria concepções ambíguas e equívocas sobre o uso do conceito de normalidade.

Duas partes da tese de doutorado foram construídas para destrinchar este problema epistemológico: uma parte revelando erros de concepção das relações entre ciência e técnica, e outra mostrando interpretações ambíguas na relação entre a norma e o normal.

A primeira parte da tese se guia pela pergunta "Seria o estado patológico apenas uma modificação quantitativa do estado normal?" (CANGUILHEM, 1995, p. 19). A partir dessa pergunta, ele aborda criticamente as reflexões propostas sobre as relações entre os conceitos de normal e patológico, os quais, desde o século XIX, eram usados para designar uma variação quantitativa de um padrão considerado como sendo referência. É justamente essa dimensão quantitativa que, na atividade terapêutica, autorizava a intervenção médica.

Para realizar essa análise crítica, Canguilhem realizou estudos sobre a obra de dois autores do século XIX que influenciaram profundamente as ciências médicas: Augusto Comte e Claude Bernard. Para ele, "esses autores desempenharam o papel de porta-bandeira" (CANGUILHEM, 1995, p. 26). Enquanto na doutrina de Comte o interesse se dirige "do patológico para o normal com a finalidade de determinar especulativamente as leis do normal", no pensamento de Bernard o interesse dirige-se "do normal para o patológico [...] como fundamento de uma terapêutica" (CANGUILHEM, 1995, p. 23). Nessa análise, Canguilhem distingue as dimensões valorativas e fenomenológicas da doença, e, conseqüentemente, coloca em questão a fundamentação quantitativista da normalidade (SERPA JUNIOR, 2006, p. 4-5):

Na discussão desses dois sentidos (do termo normal) fizemos ver o quanto esse termo é equívoco, designando ao mesmo tempo um fato e um valor atribuído a esse fato por aquele que fala, em virtude de um julgamento de apreciação que ele adota. Fizemos ver, também, o quanto esse equívoco foi 
facilitado pela tradição filosófica realista, segundo a qual toda generalidade é indício de uma essência; toda perfeição, a realização de uma essência e, portanto, uma generalidade observável de fato adquire o valor de perfeição realizada, e um caráter comum adquire um valor de tipo ideal. Assinalamos uma confusão análoga em medicina, em que o estado normal designa ao mesmo tempo o estado habitual dos órgãos e seu estado ideal, já que o restabelecimento desse estado habitual é o objeto usual da terapêutica (CANGUILHEM, 1995, p. 95-96).

$\mathrm{Na}$ segunda parte de sua tese, Canguilhem apresenta sua própria abordagem do problema, fazendo a seguinte pergunta: "Existem ciências do normal e do patológico?" (CANGUILHEM, 1995, p. 87). A discussão só será resolvida com a introdução do conceito de normatividade da vida - que irá tomar o lugar da noção de normalidade como foco central de suas preocupações. A normatividade indica que a vida estabelece normas para si mesma, ou seja, se autodetermina. Ao introduzir esse conceito, Canguilhem resgatava a idéia de autodeterminação, que era cara ao vitalismo, porém num contexto diferenciado, o da discussão do modelo organicista de Bernard e das diretrizes científicas de Comte. Sua argumentação se baseou numa crítica de determinadas categorias referenciadas no conceito de normalidade: anormal, anomalia, norma, média e patologia são termos enfocados em sua análise de dogmas subjacentes à atividade médica terapêutica (CANGUILHEM, 1995, p. 95-97).

Inicialmente, constata-se que a ambigüidade do termo normal não deve ser eliminada, mas problematizada. Em medicina, costuma-se identificar o estado normal do corpo humano com o estado que se deseja restabelecer, no caso de acometimento de doenças. Um primeiro problema se apresenta: "mas será que se deve considerá-lo normal porque é visado como fim a ser atingido pela terapêutica, ou pelo contrário, será que a terapêutica o visa justamente porque ele é considerado como normal pelo interessado, isto é, pelo doente?" (CANGUILHEM, 1995, p. 95-97).

Canguilhem assume que "a atividade valorativa atribuída a um fato biológico só poder ser feita por 'aquele que fala', evidentemente um homem". Ora, continua ele, "a medicina existe como arte da vida porque o ser vivo considera, ele próprio, como patológicos certos estados ou comportamentos que, em relação à polaridade dinâmica da vida, são apreendidos sob a forma de valores negativos". 
Essa proposição conduz ao segundo problema: "será que há um efeito espontâneo que prolonga a vida, próprio da vida, que é mais ou menos lúcido para o ser humano na luta contra os obstáculos à sua manutenção e desenvolvimento, e que é tomado como norma?" Uma resposta se apresenta: "o restabelecimento de um ser vivo traduz um fato fundamental da vida, que a vida não é indiferente às condições nas quais ela não é possível, dado que a vida é polaridade, isto é, que a vida é de fato uma atividade normativa".

A discussão sobre o normal e o patológico conduz Canguilhem ao conceito de normatividade da vida, que se apresenta como sendo também bivalente: seria um princípio ontológico, intrínseco à própria vida, e também um princípio epistemológico, atribuído à vida pelo ser humano (o médico, e/ou seu paciente, e/ou qualquer outro observador da vida). Ele apresenta ambas as possibilidades numa pergunta retórica: "Propomos falar sobre uma normatividade biológica [...] emprestamos assim às normas vitais um conceito humano, ou queremos saber como é que a normatividade essencial se explica à consciência humana, que de certo modo está em germe na vida?" (CANGUILHEM, 1995, p. 95-97). A resposta a esta pergunta só poderia ser: ambas as alternativas são verdadeiras! Contudo, devemos ressaltar a originalidade da segunda alternativa, que constituiria o núcleo central da epistemologia de Canguilhem: a consciência humana como expressão do processo de auto-organização da vida.

\section{Normatividade e polaridade da vida}

Ao inferir, em sua análise crítica da normatividade médica, a existência de uma normatividade da vida, teria Canguilhem tendido ao vitalismo? Sua concepção de vida já havia sido anunciada em 1943, na idéia mais geral de polaridade da vida, significando que a vida ora participa da Natureza, ora segue suas próprias normas:

A polaridade dinâmica da vida e a normatividade que a traduz explicam um fato epistemológico cuja importância Bichat havia sentido plenamente. Existe patologia biológica, mas não existe patologia física, nem química, nem mecânica [...]. Pode-se dizer que Aristóteles acreditara outrora numa mecânica patológica, já que admitia dois tipos de movimentos: os movimentos naturais, pelos quais um corpo retoma seu lugar próprio e onde fica em repouso, como a pedra se dirige para "o baixo terrestre" e o fogo para "o alto celeste"; e os movimentos violentos pelos quais um corpo é afastado de seu próprio lugar, 
como quando se joga uma pedra para o ar. Pode-se dizer que o progresso do conhecimento físico consistiu em considerar todos movimentos como naturais, isto é, conforme as leis da natureza e que, da mesma forma, o progresso do conhecimento biológico consiste em unificar as leis da vida natural e da vida patológica. É justamente com essa unificação que Comte sonhava e que Claude Bernard vangloriou-se de ter realizado (como vimos). Às reservas que, então, julgamos necessárias expor, acrescentamos ainda o seguinte: a mecânica moderna, baseando a ciência do movimento no princípio da inércia, tornava absurda, com efeito, a distinção entre os movimentos naturais e os movimentos violentos, já que a inércia é precisamente a indiferença em relação às direções e às variações do movimento. Ora, a vida está bem longe de uma tal indiferença em relação as condições que lhe são impostas; a vida é polaridade. O mais simples dos aparelhos biológicos de nutrição, de assimilação e de excreção traduz uma polaridade. Quando os dejetos da assimilação deixam de ser excretados por um organismo e obstruem ou envenenam o meio interno, tudo isso, com efeito, está de acordo com a lei (física, química etc.), mas nada disso está de acordo com a norma, que é a atividade do próprio organismo. Este é o fato simples que queremos designar quando falamos em normatividade biológica (CANGUILHEM, 1995, p. 97-98).

Nessa longa citação estão sintetizados alguns dos principais dilemas teóricos da biologia moderna, principalmente a tensão entre a visão finalista de Aristóteles e o mecanicismo de física newtoniana. Ao invés de simplesmente se engajar como mais um defensor da teleologia, e de seu respectivo fundamento - o princípio vital -, Canguilhem procura não só reconhecer a tensão conceitual existente, como também reelaborá-la em termos de uma concepção de polaridade da própria vida. Deste modo, o problema epistemológico que era objeto de sua análise crítica é entendido como decorrente de um estado de coisas intrínseco à própria vida.

Canguilhem reconhece esta situação nos escritos de 1955 (A formação do conceito de reflexo nos séculos XVI e XVII), procurando recusar a pecha de vitalista:

Pouco importa ser ou não tido como vitalista ou pecha semelhante que se queira atribuir com esse adjetivo. A rigor, o termo vitalista só deveria servir para designar uma teoria biológica, ou uma filosofia do biólogo, se tal empreendimento tem um sentido para ele, e não uma filosofia da biologia, único empreendimento possível para um filósofo, porém não confundido 
com uma biologia de filósofo, que seria um projeto monstruoso. $\mathrm{O}$ fato de se interessar por uma família de espíritos e de fazê-la parecer viva quando muitos a crêem morta não conduz obrigatoriamente a uma identificação mágica com ela. Se então nos esforçamos, tanto nesse presente estudo como em outros, a defender a biologia dos vitalistas contra a acusação de aberração ou de esterilidade, não é absolutamente porque pensemos estar na posse de uma chave vitalista dos problemas colocados para a inteligência pela vida. Nós não pensamos ter a chave, pela boa razão que nós não acreditamos nas portas misteriosas da vida. Pode-se admitir que a vida desconcerte a lógica, sem que por isso acreditemos ser preferível renunciar à formação de conceitos para procurar alguma chave perdida. Pensamos também que uma convicção vitalista não tem a prerrogativa de gerar no biólogo, diante os problemas que a vida lhe coloca, a preguiça e a idiotice. Existem alguns exemplos que mostram o contrário (CANGUILHEM, 1955, p. 1).

Portanto, Canguilhem não seria o advogado de uma medicina vitalista vide discussão em Serpa Junior (2006, p. 8), Ferraz (1994, p. 6 e seguintes), mas sim de uma reflexão epistemológica sobre a vida que não se prendesse às categorias mecanicistas. Para ele, enfim, o vitalismo seria apenas "a expressão da confiança do ser vivente na vida, da identidade da vida consigo mesma no vivente humano, consciente de viver" (CANGUILHEM, 1952, p. 101).

Quando Canguilhem assume a direção do Institut d'Histoire des Sciences et des Techniques, da Universidade de Paris, passa a entender como sendo primordial, na construção de seu pensamento, distinguir o progresso efetivado pelas ciências biológicas daquele realizado pelas ciências médicas. Na coletânea publicada em 1977 (CANGUILHEM, 1977), o filósofo enfatiza a instância epistemológica no trabalho historiográfico voltado às ciências da vida. Entre 1969 e 1976, ele explorara uma gama de exemplos historiográficos sobre a ideologia no campo da ciência, especificamente na Medicina e Biologia. No entanto, o princípio ontológico de normalidade da vida ainda desempenhava papel central em sua argumentação.

Nesses trabalhos, Canguilhem reitera que "normal" é um termo ambíguo, que pode ser usado tanto para a descrição de um fato, como para a atribuição de um valor (i.e., para uma avaliação do fato). Normal é aquilo que deve ser (valor), mas também é entendido como aquilo que se encontra na média (fato). O uso avaliativo é distinto do uso quantitativo de normalidade. A concepção quantitativa de normal é descritiva, na medida em que informa o quanto se 
afasta da posição normal, mas somente o recurso a um valor pode servir de referência para se avaliar em que medida de afastamento do normal ingressamos no domínio do patológico.

Por outro lado, com base no conceito de normatividade se poderia compreender o fenômeno da vida em sua racionalidade intrínseca. A normatividade está presente fenomenologicamente no próprio ser vivente e na vida: "a vida não é indiferente às condições nas quais ela é possível...é polaridade [...] em resumo, a vida é, de fato, uma atividade normativa" (CANGUILHEM, 1995, p. 96); e é extensível a todos seres vivos: "Viver é, mesmo para uma ameba, preferir e excluir" (CANGUILHEM, 1995, p. 105).

Tal distinção conceitual entre "normalidade" e "normatividade" teria importância para a racionalidade médica, à medida que se procure compreender a atividade terapêutica dentro do campo maior das ciências da vida (LACEY, 1998). Dessa distinção decorre uma outra distinção feita por Canguilhem entre patologia e anomalia. A anomalia designaria uma variação, diferença, descontinuidade espacial e/ou morfológica da espécie, que é valorizada negativamente pela própria vida - ou seja, a anomalia é um fenômeno intrínseco ao processo vital. Já no termo patológico, considera-se o organismo em relação ao meio, podendo-se ou não ser patológico, dependendo as variações do meio ambiente. Ou seja, a patologia é um termo empregado num julgamento extrínseco ao organismo, quando tomado em referência ao meio em que se situa.

Desse raciocínio surgem modificações da proposta apresentada na tese de 1943, buscando um acordo com o progresso das ciências médicas em 1977. No contexto da descoberta científica na medicina, o conceito de normal passa a ser entendido como referente ao contexto da interação entre o organismo e o meio, e não do organismo isoladamente. O meio é normal quando o organismo desenvolve sua vida em acordo com sua norma. A anomalia exprime uma outra norma de vida que se impõe; ela poderá ser inferior, igual ou superior à norma anterior, correspondendo respectivamente aos modos patológico, normal e favorável à fecundidade e variabilidade da vida. Neste caso, o patológico não é ausência de uma norma biológica, mas a ocorrência de uma norma recusada pela vida. Assim, o anormal não é a ausência, mas a restrição da normatividade vital:

Nem toda anomalia é patológica, mas só a existência de anomalias é que propiciou uma ciência especial das anomalias, que tende usualmente - pelo fato de ser ciência - a banir, da definição da anomalia, qualquer implicação normativa [...] a anomalia é a conseqüência de variação individual que impede 
dois seres de poderem se substituir um ao outro de modo completo [...]. No entanto, diversidade não é doença. $\mathrm{O}$ anormal não é patológico. Patológico implica pathos, sentimento direto e concreto de sofrimento e de impotência, sentimento de vida contrariada [...]. Sem dúvida, há uma maneira de considerar o patológico como normal, definindo o normal e o anormal pela freqüência estatística relativa [...] em certo sentido pode-se dizer que a saúde perfeita contínua é um fato anormal (CANGUILHEM, 1995, p. 106).

\section{Considerações finais: sobre a normatividade da vida e a auto-organização}

O conceito de causa final, de Aristóteles, assim como os postulados de um princípio vital, pelos adversários do modelo mecanicista da ciência moderna, tinham em comum o caráter fundamentalista atribuído à teleologia. Ou seja, a existência de uma meta ou telos para a atividade dos seres vivos era entendida como preexistente e condicionante desta atividade.

No conceito de normatividade da vida de Canguilhem podemos notar uma inversão dos fatores, em que o processo vital antecede $e$ determina a emergência de normas, as quais podem ser alteradas conforme os caminhos percorridos.

A distinção entre uma teleologia fundamental e uma teleologia derivada de um processo encontra um paralelo em estudos contemporâneos de fenômenos de auto-organização (AO), em particular na teoria proposta por Michel Debrun (1996). Debrun distingue entre dois tipos de AO. Na AO primária, um sistema - i.e., uma rede de relações - se forma a partir das interações que se estabelecem entre diversos elementos anteriormente independentes entre si. Já na AO secundária, um sistema já constituído, que seja aberto a interações com seu meio (o que é uma condição necessária, tendo em vista a Segunda Lei da Termodinâmica), passa por transformações organizacionais que decorrem primordialmente de relações intrínsecas (aquelas que são estabelecidas ao longo do tempo, entre os componentes do sistema), e não de uma ação extrínseca (i.e., de fatores externos ao sistema, o que - se fosse o caso - caracterizaria uma hetero-organização).

A partir da teorização sobre a AO realizada por Debrun, podemos fazer uma distinção mais clara entre a concepção de teleologia defendida pelos vitalistas e o conceito de normatividade da vida de Canguilhem. O princípio 
vital, que fundamenta as ações teleológicas, é concebido como um princípio metafísico (ou, em determinadas versões, como uma força da natureza ainda não tematizada pela Física) que se situa extrinsecamente ao ser vivo, e conduz a atividade deste ser em direção a uma meta ou conjunto de metas. Já a normatividade da vida, ao contrário, emerge da própria atividade do ser vivo, se manifestando como escolha ou mesmo como intenção consciente.

Desta forma, podemos conjeturar que a normatividade da vida se situaria no plano da AO secundária, na qual um sistema já formado - um organismo vivo - estabelece, a partir de sua própria atividade ao longo do tempo (ou seja, a partir das interações entre seus componentes e do sistema com o ambiente), as metas que estabelece para si. Nesta concepção, tais metas são reais, mas não se situam num plano superior ao do processo da vida. Por outro lado, nas concepções vitalistas o princípio vital atuaria já no plano da AO primária, dirigindo o desenvolvimento do organismo e/ou a evolução das espécies. Neste sentido, tais processos de desenvolvimento e evolução não seriam verdadeiramente auto-organizados, uma vez que seriam dirigidos por um princípio externo ao sistema que se constitui e se transforma ao longo do tempo.

\section{Referências}

BAYLISS, L. E. Living control systems. London: English University Press, 1966.

BERNARD, Claude. Introduction à l'étude de la médecine expérimentale, 1865. Disponível em: <http://classiques.uqac.ca/classiques/bernard_claude/ intro_etude_medecine_exp/intro_etude.html >.Acesso em: 18 ago. 2006.

CANGUILHEM, Georges. Aspects du vitalisme. In: . La connaissance de la vie. Paris: J. Vrin, 1992. p. 105-128.

Ideologia e racionalidade nas ciências da vida. Lisboa: Edições 70, 1977.

La formation du concept de réflexe aux XVII et XVIII siècles. Paris: Presses universitaries de France, 1955.

O normal e o patológico. Rio de Janeiro: Forense Universitária, 1995.

DEBRUN, M. O conceito de auto-organização. In: DEBRUN, M; GONZÁLES, M. E. Q.; PESSOA JUNIOR, O. (Org.). Auto-organização: estudos interdisciplinares. Campinas: Centro de Lógica e Epistemologia, 1996. 
FERRAZ, C. H. O valor da vida como fato: uma crítica neopragmática à epistemologia da vida de Georges Canguilhem. Rio de Janeiro: UERJ, IMS, 1994. (Série Estudos em saúde coletiva, n. 105).

HULL, David L. Philosophy of biological science. New York: PrenticeHall, 1974.

LACEY, Hugh. Valores e atividades científica. São Paulo, Discurso, 1998.

SERPA JUNIOR, O. D. Indivíduo, organismo e doença: a atualidade de "O Normal e o Patológico" de Georges Canguilhem. Psicologia Clínica, Rio de Janeiro, v. 15, n. 1, 2006. Disponível em: <http://www.puc-rio.br/sobrepuc/ depto/psicologia/Octavio.html>. Acesso em: 20 ago. 2006.

WEYDERT, A. How can we understand the construction of our organism? Comptes Rendus Biologies, Paris, France, n. 327, p. 421-429, 2004.

\section{NOTAS}

- Professor assistente doutor, Departamento de Saúde Pública, Faculdade de Medicina de Botucatu, UNESP. Endereço eletrônico: puttini@fmb.unesp.br.

- Professor adjunto, Departamento de Educação, Instituto de Biociências, UNESP. Endereço eletrônico: apj@ibb.unesp.br.

${ }^{1}$ Agradecemos o apoio do CNPq, que concedeu Bolsa de Produtividade em Pesquisa ao pesquisador Alfredo Pereira Junior, co-autor deste artigo. 


\section{ABSTRACT}

Beyond mechanism and vitalism: the normativity of life" according to Georges Canguilhem

We discuss the epistemology of the sciences of life and health elaborated by Georges Canguilhem. First we review his criticism to mechanicist concepts of normality and pathology, and his position regarding vitalism. We suggest that, when emphasizing the concept of "normativity of life", Canguilhem goes beyond the dichotomy of mechanism and vitalism. We make a brief comparison of his concept of "normativity of life" with the contemporary concept of "self-organization" proposed by Michel Debrun, arguing that the emergency of the vital norm occurs on the second stage of the process of life self-organization and therefore such normativity does not have the vitalist connotation erroneously attributed to Canguilhem.

Key words: normativity of life; normal; pathological; mechanism; vitalism, self-organization. 